\title{
Beyond Physicalism and Dualism?
}

Putnam's Pragmatic Pluralism and the Philosophy of Mind

\section{David Ludwig}

\section{(2) OpenEdition}

Electronic version

URL: http://journals.openedition.org/ejpap/847

DOI: $10.4000 /$ ejpap.847

ISSN: 2036-4091

\section{Publisher}

Associazione Pragma

Electronic reference

David Ludwig, "Beyond Physicalism and Dualism? », European Journal of Pragmatism and American Philosophy [Online], III-2 | 2011, Online since 29 December 2011, connection on 01 May 2019. URL : http://journals.openedition.org/ejpap/847 ; DOI : 10.4000/ejpap.847

This text was automatically generated on 1 May 2019.

\section{c) (†) $९$}

Author retains copyright and grants the European Journal of Pragmatism and American Philosophy right of first publication with the work simultaneously licensed under a Creative Commons AttributionNonCommercial-NoDerivatives 4.0 International License. 


\title{
Beyond Physicalism and Dualism?
}

\author{
Putnam's Pragmatic Pluralism and the Philosophy of Mind
}

\section{David Ludwig}

1 Since the second half of the 20th century, philosophers of mind commonly consider physicalism and dualism as their only serious options: mental states are either material or immaterial states. While physicalism is usually taken as the default position, dualism looms in the background as the price philosophers have to pay if they abandon the goal of a naturalized mind. From a historical point of view, the almost exclusive opposition between physicalism and dualism is surprising as it ignores influential philosophical traditions such as idealism, neutral monism, and anti-metaphysical methodologies. However, none of these options have gained much support in contemporary philosophy of mind.

2 The emergence of physicalism as the default position in the philosophy of mind is closely related to the scientific realism and optimistic reductionism of early post-war philosophy in America and Australia. One of the most vivid illustrations of this early reductionist enthusiasm is Paul Oppenheim's and Hilary Putnam's 1956 article on the "Unity of Science as a Working Hypothesis," which outlined the idea that all laws of science are reducible to the most fundamental laws of physics. Proposing different "reductive levels" such as "social groups," "living things," and "cells," Oppenheim and Putnam assumed that every level is reducible to the next more fundamental level. By taking reductions to be transitive, they concluded that every level is at least in principle reducible to the most fundamental level of "particle physics" (Oppenheim \& Putnam 1956: 9).

In early post-war philosophy, behavioural psychology and neurobiology seemed to be the most promising disciplines for a reductive explanation of the mind and offered the foundations for the philosophical theories of behaviourism and type identity. The situation changed in the late 1950s when early cognitive scientists challenged the behaviouristic orthodoxy and claimed that internal representations had to be considered respectable scientific entities. In a series of papers published throughout the 1960s, Putnam outlined a philosophical interpretation of this cognitive revolution by taking mental states to be functional states rather than behavioural dispositions or brain states (reprinted in Putnam 1975a). However, these differences should not obscure a more 
fundamental agreement: behaviourism, type identity theory, and functionalism share the conviction that the sciences offer sufficient resources to explain the human mind as part of an ultimately physical reality.

4 Although Hilary Putnam has played a significant role in shaping philosophy of mind in the second half of the 20th century, he has more recently criticised its metaphysical foundations as fundamentally flawed. "[N]either the classical problems in the philosophy of mind nor the 'philosophical positions' they give rise to are completely intelligible" (Putnam 1999: 78). According to Putnam, we neither have to identify mental and physical states nor do we have to consider the mind as ontologically distinct from the physical world. Instead of physicalism or dualism, Putnam suggests a pragmatistic stance according to which different conceptual systems are justified in different contexts and do not have to be reduced to some single and fundamental ontology: "Mind talk is not talk about an immaterial part of us but rather a way of describing the exercise of certain abilities we posses, abilities that supervene upon the activity of our brains and upon all our various transactions with the environment but that do not have to be reductively explained using the vocabulary of physics and biology, or even computer science" (Putnam 1999: 38).

\section{Conceptual Relativity}

5 Putnam's discontent with mainstream philosophy of mind dates back to the 1980s, when he started to criticise not only his earlier functionalist account but also the very the idea of a "naturalized intentionality." As Putnam puts it in Representation and Reality: "I do not see any possibility of a scientific theory of the 'nature' of the intentional realm, and the very assumption that such a theory must be possible if there is anything to intentional phenomena at all is one that I regard as wholly wrong" (Putnam 1988: 109).

6 According to Putnam, the alternative to a "scientific theory of the 'nature' of the intentional realm" is not dualism but an "alternative picture" (Putnam 1988: 107) that requires the reconsideration of the metaphysical foundations of contemporary philosophy of mind. Putnam argues that physicalism and dualism share the assumption that there is one single and absolute description of reality while they disagree on how this description looks like. Physcialists claim that the absolute description of reality will only involve physical concepts while dualists assume that an absolute and complete description of reality will require physical and mental concepts. Contrary to physicalism and dualism, Putnam's "alternative picture" rejects the very idea one single and absolute ontology and instead accepts that we can describe reality in terms of different but equally fundamental vocabularies.

7 At the core of Putnam's alternative picture lies his argument for "conceptual relativity" which he has developed and defended over the course of 20 years (Putnam 1987, 1988, 2004). The general idea of conceptual relativity can be illustrated with everyday examples such as

a room with a chair, a table on which there are a lamp and a notebook and a ballpoint pen, and nothing else, and I ask, 'How many objects are there in this room?' My companion answers, let us suppose, 'Five.' 'What are they?' I ask. 'A chair, a table, a lamp, a notebook, and a ballpoint pen.' 'How about you and me? Aren't we in the room?' My companion might chuckle. 'I didn't think that you 
meant I was to count people as objects. Alright, then, seven.' 'How about the pages

of the notebook?' [...] (Putnam 1988: 110) the imagined room. In some situations we might be inclined to count people as objects; in other situations we focus only on inanimate things. In some situations, we may count individual pages as objects, whereas in others this may not occur to us. Taking this even further, if we would put one of those pages under a microscope we would again create a very different context, in which we may feel inclined to count other objects, such as cells. It seems trivial that the different descriptions can be equally correct. How someone describes Putnam's room depends on the context of the conversation and the linguistic preferences of the speaker. One way or another, our ordinary language allows us to describe Putnam's room in different and equally correct ways.

philosophers insist that Putnam's example only shows that our ordinary language is fuzzy and doesn't help with the ontological question of how many objects really exist. In his 1987 paper "Truth and Convention," Putnam introduced a simple example and two ontological theories which are commonly known as "ontological nihilism" and "ontological universalism." Consider a world with three individuals (x1, x2, and x3) and the question of how many objects exist. The obvious difficulty is whether the individuals compose new objects such as " $\mathrm{x} 2+\mathrm{x} 3$ " or " $\mathrm{x} 1+\mathrm{x} 2+\mathrm{x} 3$." The most common solutions are the most radical ones: While Nihilists argue that objects never compose new objects (e.g. Dorr \& Rosen 2002), universalists claim that objects always compose new objects (e.g. Van Cleve 2008). universalist assumes that seven objects $(\mathrm{x} 1, \mathrm{x} 2, \mathrm{x} 3, \mathrm{x} 1+\mathrm{x} 2, \mathrm{x} 2+\mathrm{x} 3, \mathrm{x} 1+\mathrm{x} 3, \mathrm{x} 1+\mathrm{x} 2+\mathrm{x} 3)$ exist. The controversy is not limited to obscure philosophical examples but extends to the real world. Nihilists claim that only elementary particles are objects and conclude that ordinary objects such as chairs or oranges do not really exist. The ontological claims of universalists are equally shocking as they claim that every object composes a new object with every other object. There is even an object composed of your nose and Immanuel Kant's grave.

11 Putnam argues that these ontological theories are not fully intelligible. Consider the example in which the nihilist claims that three objects exist while the universalist assumes that seven objects exist. Nihilists and universalists both know that three individuals exist and they also agree on most of their properties such as their undividability or their spatial positions. Given their agreements it becomes increasingly unclear what they are disagreeing about as they simply seem to offer equally acceptable descriptions of the same situation. There is nothing wrong with counting only individuals as objects and there nothing wrong with counting compositions as objects, either. In some contexts nihilism or universalism may offer a more useful description, but there is no point in debating how many objects really exist.

12 The situation is equally puzzling in the case of real world applications of nihilism and universalism. If you think that there is a beer in your fridge while your friend thinks that you ran out of beer, you have a perfectly understandable disagreement. When nihilists claim that there is no beer in your fridge, something else is going on because they claim that beer (contrary to "beer-wise arranged particles") does not really exist. However, what does it mean that beer does not really exist while beer-wise arranged particles exist? It seems that we do not have a grip on what it would be for a beer to really exist and 
nihilists do not offer any explanations that help to understand their ontological claims (Chalmers 2009: 109). Universalists face the same problem: what does it mean that your nose and Immanuel Kant's grave really compose a new object? Do we understand the difference between them composing an object and them not composing an object?

What is the alternative to this ontological debate? According to Putnam, the alternative is to embrace "conceptual relativity" and to dismiss the idea of one single and absolute ontology. As long as one accepts the ideal of an absolute ontology, the question of how many objects really exist seems unavoidable. Contrary to this ontological standpoint, Putnam's theory of conceptual relativity argues that there is not one single correct way to talk about the existence of objects. Some ways to talk about objects may be more useful than others, but that does not mean that there is one fundamental or absolute description.

Conceptual relativity is not limited to an esoteric ontological debate about the number of objects but has general consequences for the understanding of ontology. If ontology aims at one single and absolute description of reality, then there is something fundamentally wrong with the whole project:

In place of Ontology (note the capital 'O'), I shall be defending what one might call pragmatic pluralism, the recognition that it is no accident that in everyday language we employ many different kinds of discourses, discourses subject to different standards and possessing different sorts of applications, with different logical and grammatical features - different 'language games' in Wittgenstein's sense - no accident because it is an illusion that there could be just one sort of language game which could be sufficient for the description of all of reality! (Putnam 2004: 21)

\section{Pragmatic Pluralism and Reductive Explanation}

While Putnam's discussion of conceptual relativity has profoundly influenced contemporary debates about realism and ontology, philosophers of mind tend to ignore these issues and seem to consider them as irrelevant for their "philosophical subdiscipline." Contrary to this assumption, I want to argue that conceptual relativity is of crucial importance for Putnam's claim that the standard positions in the philosophy of mind are not completely intelligible. However, it will be necessary to generalize the discussion and to focus on the idea of conceptual or pragmatic pluralism as it has been introduced by Putnam in Ethics without Ontology (2004):

In Representation and Reality I counted the fact that we might describe "the contents" of a room very differently by using first the vocabulary of fundamental physical theory and then again the vocabulary of tables and lamps and so on as a further instance of conceptual relativity and this, I now think, was a mistake, although it is an instance of a related and wider phenomenon I should have called conceptual pluralism. The fact that the contents of a room may be partly described in two very different vocabularies cannot be an instance of conceptual relativity in the sense just explained, because conceptual relativity always involves descriptions which are cognitively equivalent [...] but which are incompatible if taken at face value. (Putnam 2004: 48)

Putnam's differentiation between conceptual relativity and conceptual pluralism corresponds with the distinction between horizontal and vertical pluralism as discussed by Huw Price (1992) and Michael Lynch (2001: 6-8). Horizontal pluralism is the claim that there can be different but equally fundamental descriptions on one conceptual level while 
vertical pluralism assumes different but equally fundamental descriptions on different conceptual levels. A simple way to illustrate the distinction is Putnam's example of a room with a chair, a table, a lamp, a notebook, and a ballpoint pen. The fact that we can count the objects in the room in different ways is an instance of horizontal pluralism. Vertical pluralism claims that we can describe the room on different conceptual levels such as every day language or particle physics. Figure 1 offers a simple illustration of the distinction:

Figure1

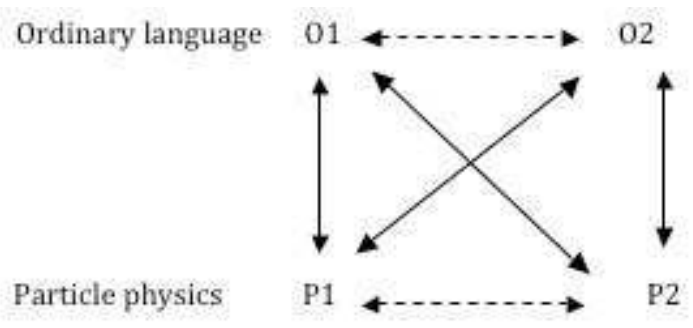

Horizontal pluralism claims that there can be different but equally fundamental descriptions in terms of every day language (01 \& 02) or particle physics (P1 \& P2) and describes the relation represented by the dashed lines. Vertical pluralism claims that the same situation can be described on different but equally correct conceptual levels (P1 \& 01, P1 \& 02, P2 \& 01, P2 \& 02) and describes the relation represented by the solid lines.

Horizontal pluralism is philosophically interesting because two descriptions on the same conceptual level often seem to contradict each other: how can there be exactly five objects and exactly seven objects in the same room at the same time? The puzzlement vanishes when we realize that there are different correct ways to talk about the existence of objects. If we only count macroscopic inanimate things in Putnam's room, there will be five objects. If we count macroscopic inanimate things and people, there will be seven objects. If we also count microscopic things like cells, there will be far more objects. And so on.

Contrary to horizontal pluralism, vertical pluralism might seem to state an obvious and uncontroversial fact: who would deny that we can describe the world in terms of different concepts such as ordinary concepts and the concepts of particle physics? of course, some philosophers reject conceptual systems such as "folk psychology" as dysfunctional, but even the most dedicated eliminative materialist would not deny that we need different conceptual resources. An eliminative materialist might argue that a psychotherapist should work on a purely neurological level, but she would certainly not suggest replacing psychological concepts with microphysical concepts.

The pragmatic need for a plurality of conceptual systems is undeniable and might raise the question whether vertical pluralism is an interesting philosophical position. However, Putnam's pragmatic pluralism goes an important step further by claiming that none of these conceptual systems can claim ontological priority in the sense of providing an absolute description of reality. "That we can use [different conceptual] schemes without being required to reduce one or both of them to some single fundamental and universal ontology is the doctrine of pluralism" (Putnam 2004: 49).

Pragmatic pluralism has important ontological as well as epistemological implications. Ontologically, pragmatic pluralism challenges both physicalism and dualism. Contrary to 
physicalists, Putnam rejects the idea that physical concepts are ontologically prior to all non-physical concepts. In the case of a room that is described in terms of ordinary language and particle physics, we simply have two correct descriptions of reality and do not need to claim that our ordinary concepts are somehow ontologically inferior. Putnam's examples of conceptual relativity can illustrate the argument: there is no need to decide whether nihilists or universalists (or some one else) offer the fundamental description of reality as there are simply different ways to talk about the existence of objects. In the same sense, there is no need to offer one single fundamental description of the room that can be described in terms of ordinary language and particle physics. Instead, we have to take the plurality of conceptual systems seriously. Some conceptual systems will turn out more useful than others in a given context but there is simply no point in claiming that one of them describes the world in terms of an absolute ontology. Although Putnam denies the ontological priority of the physical description, he does not subscribe to a version of dualism or ontological pluralism, either. Ontological pluralism assumes that different and equally fundamental conceptual systems refer to ontologically distinct realms of reality. A clear example is Karl Popper's theory of three worlds in which three irreducible conceptual systems correspond with three ontologically distinct kinds of entities (Popper 1978). Contrary to ontological pluralism and dualism, Putnam does not assume that equally conceptual systems imply ontologically distinct realms of reality. Again, conceptual relativity can help to understand the argument. In the case of a room with three individuals, nihilists and universalists offer different but equally fundamental descriptions. However, that does not mean that there are two ontologically distinct realms of reality - a nihilistic reality with three objects and a universalistic reality with seven objects. In the same sense, pragmatic pluralism does not imply ontological gaps between the referents of different concepts. If we describe a room in terms ordinary language and particle physics we do not describe two ontologically distinct realms of reality but we describe the same room in terms of different conceptual systems.

Pragmatic pluralism undermines the common framework of physicalism and dualism by denying that we need to describe reality in terms of one single and absolute ontology. Putnam's alternative picture, however, does not only challenge ontological but also epistemological assumptions: as long as philosophers of mind take a physicalistic ontology as the default position, the need for reductive explanations seems obvious. If we assume that a fundamental physical theory describes everything that really exists, we also have to be able (at least in principle) to explain everything else in terms of that physical theory. A physicalist might grant that we can describe humans in terms of different conceptual systems such as particle physics, biology, scientific psychology, folk psychology, and so on. However, if these descriptions are true and a fundamental physical theory describes everything that really exists, then it must be possible to reduce them to the fundamental physical theory.

Given the physicalistic framework of an absolute physical ontology, reductionism appears as an inevitable consequence. However, within Putnam's alternative picture of pragmatic pluralism, the reductionist argument loses its persuasiveness. A pragmatic pluralist will admit that the world can be described with physical concepts but reject their ontological priority and the idea that all non-physical concepts must be considered derivative. An example can help to illustrate the difference: we can describe humans as physical systems, biological organisms, psychological subjects, and so on. If we assume that 
humans are really just physical systems, then we have to explain how our biological or psychological descriptions can fit in this ontological framework. Pragmatic pluralism accepts that we can describe humans also as physical systems but denies that this description is ontologically prior to our biological or psychological description. But if we assume that the physical description is not ontologically prior to other descriptions, the need for reductive explanations vanishes.

To say that pragmatic pluralism rejects reductionism does not mean that reductive explanations cannot be successful. However, there is no reason to believe that they must be successful.

\section{The Limits of Identity Talk}

According to Putnam, pragmatic pluralism offers an alternative to both dualism and physicalism by undermining their common assumption of an absolute ontology. Dualists make the mistake of considering the existence of irreducible conceptual systems as sufficient for the existence of non-physical entities. Physicalists make the opposite mistake of taking the rejection of non-physical entities to imply one single and absolute physical perspective. Both miss the possibility of different descriptions of the same reality which are neither reducible to an absolute ontology nor refer to ontologically distinct realms of reality.

Most philosophers of mind won't be convinced by Putnam's alternative picture. One way of articulating doubts is to ask whether pragmatic pluralists accept the identity of mental and physical states. The question seems to imply a dilemma for Putnam's rejection of physicalism and dualism: if he accepts the identity of mental and physical states, then his theory leads to a version of non-reductive physicalism. If he denies the identity of mental and physical states, then pragmatic pluralism is committed to the existence of nonphysical entities and therefore some kind of dualism. As Putnam puts it: "Much of the appeal of the 'identity theory' has always had its source in the fear of being driven to the supposed opposite horn the dilemma that either we must opt for some form of identity theory (or perhaps eliminative materialism), or else be forced back to the dark old days of dualism" (Putnam 1999: 37).

28 A pragmatic pluralist may respond to this objection by accepting the identity of mental and physical states while insisting that identity is not sufficient for physicalism. Identity is a symmetrical relation while physicalists assume the priority of the physical. Identity without the priority of the physical might lead to some form of neutral monism but not to physicalism. Therefore, physicalists do not only have to establish the identity of mental and physical states but have to justify the priority of the physical.

Although a pragmatic pluralist might accept the identity of mental and physical states, Putnam's response is much more radical as he argues "that the notion of identity has not been given any sense in this context. We cannot, for example (as I once thought we could), employ the model of theoretical identification derived from such famous successful reductions such as the reduction of thermodynamics to statistical mechanics, because that model assumes that both the reduced theory and the reducing theory have a well-defined body of laws" (Putnam 1999: 85). According to Putnam, we do not really understand the identity question and we can avoid the dilemma by avoiding confused (and confusing) questions. Identity talk makes perfect sense in some contexts such as 
theoretical identification but that doesn't mean that identity talk makes sense in every context.

Of course, theoretical identification as described by Putnam is not the only way to establish an identity relation. If we identify "Hilary Putnam" and "the author of Renewing Philosophy," there will be no theoretical identification involved. A different model for the identification of entities is suggested by the principle of the Identity of Indiscernibles: if we can establish that everything that is true about $\mathrm{x}$ is also true about $\mathrm{y}$, then we can conclude that $\mathrm{x}$ and $\mathrm{y}$ are identical. "Hilary Putnam" and "the author of Renewing Philosophy" are both born in 1926, married to Ruth Anna Putnam, friends of Jürgen Habermas, and so on. If we find out that everything that is true about Hilary Putnam is also true about the author of Renewing Philosophy, we can conclude that they are in fact the same person.

31 Although the Identity of Indiscernibles offers another model for identity talk, it doesn't prove that identity claims make sense in every context. Putnam's rejection of the identity question may seem puzzling at first but I think that his stance can be clarified by reconsidering his examples for pragmatic pluralism. In the case of a room that can be described in terms of ordinary language and particle physics, one might wonder whether ordinary objects such as tables are identical with arrangements of elementary particles.

The converse of the Identity of Indiscernibles tells us that identity entails indiscernibility: if $\mathrm{x}$ and $\mathrm{y}$ are identical, everything that is true about $\mathrm{x}$ is also true about $\mathrm{y}$. Ordinary objects and arrangements of elementary particles fail to meet this criterion: The table in the room may be five years old while the arrangement of elementary particles that constitute the table is constantly changing and certainly not five years old. There is no arrangement of elementary particles with the same life-span as the table. Therefore, not everything that is true about the table is also true about any arrangement of elementary particles and they are not identical.

Furthermore, it is not even clear what arrangement of elementary particles a table could be identified with. The spatial borders of a table are obviously sharp enough for our everyday usage but they are not sharp enough to satisfy an ontologist who wants to identify the table with one specific arrangement of elementary particles. We won't be able to tell where the table begins on a subatomic level and cannot single out one arrangement of elementary particles as identical with the table.

It is by no means a new discovery that identity talk reaches its limits when we try to describe the relation between ordinary objects and elementary particles. It is also not the only limit of identity talk as the debates about material constitution (Rudder-Baker 1997), determinates and determinables (Yablo 1992), as well as sets and sub-sets (Sanford 2005) illustrate. However, philosophers of mind still largely assume "we must opt for some form of identity theory (or perhaps eliminative materialism), or else be forced back to the dark old days of dualism" (Putnam 1999: 37). How is that possible?

The main reason seems to be the worry that the rejection of identity claims implies the assumption of new entities and an inflated ontology. If we claim that ordinary objects are not identical with arrangements of elementary particles, don't we have to assume that they are ontologically distinct and therefore constitute an additional realm of reality? The result seems to be a bizarre pluralistic ontology of countless ontologically distinct objects (see Sosa 1993: 620). 
36 Although this worry might be justified within the framework of an absolute ontology, Putnam's pragmatic pluralism offers an answer: the limits of identity talk are not explained by an inflated ontology but a plurality of ways to talk about the existence of objects. This point becomes especially clear in the case of conceptual relativity: if we consider Putnam's example of a room with three individuals, we seem to reach another limit of identity talk: the universalist's composed objects are not identical with any of the nihilist's objects. However, that doesn't mean that we need two realms of reality - one for the universalistic and one for the nihilistic objects. Rather, it means that we need to accept that there are different ways to talk about the existence of objects. While it is correct to claim that the object " $\mathrm{x} 1+\mathrm{x} 2$ " exists given the nihilist's vocabulary, the same claim would be wrong given the universalist's vocabulary. As existence claims are true or wrong relative to our conceptual decisions, we do not need an inflated absolute ontology that contains both universalist's and nihilist's objects.

The moral of these examples is that Putnam's rejection of the identity claims does not lead to dualism or an inflated ontology. The limits of identity talk are not restricted to the philosophy of mind but ubiquitous if we try to describe the relationship between different conceptual systems. According to Putnam, mind talk does not refer to a distinct realm of reality but "is rather a way of describing the exercise of certain abilities we posses" (Putnam 1999: 37). These descriptions require concepts that are very different from the concepts of particle physics and it is by no means surprising that we cannot describe the relationship between mental and physical states in terms of identity statements.

\section{Renewing Philosophy of Mind}

So far, I have tried to explain Putnam's claim "that neither the standard problems in the philosophy of mind nor the 'philosophical positions' they give rise to are really intelligible" (Putnam 1999: 112) by presenting pragmatic pluralism as an alternative to physicalism and dualism. Contrary to physicalists, Putnam does not accept the ontological priority of physical descriptions and instead insists on a "plurality of conceptual resources, of different but not mutually reducible vocabularies" (Putnam 1999: 38). Contrary to dualists, Putnam denies that irreducible concepts imply the existence of ontologically distinct realms of reality. Given these arguments, it is not hard to see why Putnam thinks that the entire discussion of the mind-body problem needs a careful reconsideration.

Some of the most common presentations of the mind-body-problem are based on the irreducibility of phenomenal or intentional states and already presuppose that irreducibility is something mysterious. Consider the case of phenomenal consciousness or qualia. Often, the problem is introduced as an "explanatory gap" between our physical (or biological or computational) and phenomenal accounts. No matter how detailed our physical descriptions are, they do not imply the existence of phenomenal consciousness. Cognitive science and neuroscience advance rapidly, but there remains the explanatory gap of an unreduced phenomenal consciousness. In the past 40 years, philosophers of mind have developed a large variety of examples and thought experiments that illustrate the explanatory gap: 
*Bats (Nagel 1974): What is it like to be a bat? Confronted with this question, we might turn to zoologists, ethologists and cognitive neuroscientists who will be able to tell us a lot about the behaviour and cognitive structure of bats, about their perception, memory, and so on. None of this, however, will imply anything about the phenomenal experience of bats. For example, scientists may inform us about the details of echolocation but they won't have anything to say about what it feels like to perceive the world by sonar. Therefore, there seems to be an unbridgeable gap between our biological knowledge and the phenomenal aspect of reality.

*Mary (Jackson 1982): Image Mary, a superscientist, who grows up in a black and white room and has never seen colours in her whole life. However, she receives an extraordinary education and learns everything about colour perception. Finally, she leaves her prison and sees colours for the first time. Although Mary had already a complete physical account colour perception before she was freed, it still seems obvious that Mary learns something new about the visual experience of colours when she sees colours for the first time. Therefore, even complete physical information not sufficient to bridge the gap to phenomenal consciousness.

*Zombies (Chalmers 1996): Imagine a philosophical zombie, i.e. a person who lacks phenomenal consciousness but has the biological and behavioural structure of a normal human being. How do we know that philosophical zombies do not exist? It seems that empirical sciences cannot answer that question as one can imagine all the physical (or biological or computational) processes without the occurrence of phenomenal consciousness. No matter how detailed a physical descry iption of humans is, nothing seems to make philosophical zombies inconceivable. Therefore, there is an unbridgeable explanatory gap between our physical and phenomenal descriptions.

43 Examples such as Nagel's bats, Jackson's Mary, and Chalmers' zombies present the mindbody problem in terms of a gap between physical and phenomenal accounts of reality. Given the assumption of a physicalistic ontology, the problem is obvious: if physicalism is true, phenomenal states are nothing but physical states. And if phenomenal states are nothing but physical states, it must be possible to explain it in terms of a physical theory.

While the "explanatory gap" remains an obvious and pressing problem for physicalism, there is nothing mysterious about the irreducibility of phenomenal consciousness in the framework of pragmatic pluralism. Pragmatic pluralism rejects the idea of one single and absolute ontology and instead insists on different but equally fundamental conceptual systems. As consequence, there is nothing surprising and certainly nothing mysterious about the fact that phenomenal concepts are not physically explicable.

Putnam's claim that the standard problems in the philosophy of mind are not fully intelligible can be partly understood by showing that many formulations of the mindbody problem depend on the assumption that irreducibility is something mysterious. If one gives up the idea that there must be a reductive explanation of the mind, neither the irreducibility of phenomenal consciousness nor the irreducibility of intentionality come as a surprise.

While the rejection of reductionism undermines many well-known formulations of the mind-body problem, philosophers of mind often argue that non-reductive theories do not constitute viable alternatives as they fail to explain mental causation. For example, Jaegwon Kim (1993: 250-5, 281-92) has argued that non-reductive theories of the mind face a "causal exclusion problem" which ultimately leads to epiphenomenalism. Consider 
a simple example of mental causation such as a headache being the cause for taking a pain killer. While the headache seems to be causally relevant, there is also a purely biological explanation of the behaviour. Thus, there are at least two potential causes:

(C1) The headache is the cause for taking a pain killer.

(C2) The biological process $b$ is the cause for taking a pain killer.

Reductive physicalists have a simple solution for the apparent overdetermination: a headache is nothing but a biological process and (C1) can be reduced to (C2). Non-reductive theories cannot make this move and seem to be committed to overdetermination. However, a systematic overdetermination would be utterly mysterious as is would imply that every mental cause is accompanied by an ontologically distinct biological cause. If there is no explanation for this systematic overdetermination, non-reductive theories end up with a bizarre metaphysical picture. But if overdetermination is not an option, non-reductive theories will have to give up either (C1) or (C2). Giving up (C2) would come at the very high price of claiming that there is no sufficient biological or physical cause of mentally caused behaviour. According to Kim, this rejection of the "causal closure of the physical domain" cannot be considered a serious option, which leaves non-reductive theories of the mind with the epiphenomenalist rejection of (C2).

Kim's exclusion argument seems to create a fatal dilemma for non-reductive theories: mental causes are either physical or non-physical causes. If they are physical causes, then non-reductive theories are wrong and we need a reductive explanation of mind. If mental causes are not physical, then they compete with physical causes for causal relevance and finally end up as causally irrelevant.

While Kim's exclusion argument might be convincing in case of some non-reductive theories, it clearly fails to threaten Putnam's pragmatic pluralism. Remember that pragmatic pluralism is not a version of dualism or ontological pluralism and does not assume that our psychological and physical concepts refer to ontologically distinct entities. Rather than postulating ontologically distinct realms of reality, Putnam insists that we can describe the same human being in terms of very different conceptual systems such as particle physics, biology, scientific psychology, folk psychology, and so on. But if there is no ontological gap between physical and mental, then there is also no systematic overdetermination but simply different and equally fundamental ways to talk about causes. As Putnam puts it by quoting John Haldane: 'there are 'as many kinds of 'cause' as there are senses of 'because" (Putnam (1999: 137), see also El-Hani and Philström (2002) for a similar response to the exclusion problem).

To clarify this argument, I want to suggest a thought experiment. Imagine that the Linnaean Society is concerned about the declining hedgehog population in Malta and sends two biologists to the island to investigate the phenomenon. While the biologists conduct their field work together, they write two separate reports. Surprisingly, they seem to come to contradictory results:

51 Biologist I: The genus of kites (Milvus) is the cause of the declining hedgehog population. Since kites hunt hedgehogs and are common in Malta, the hedgehog population is under pressure.

52 Biologist II: The genus of hawks (Accipitrinae) is the cause of the declining hedgehog population. Since hawks hunt hedgehogs and are common in Malta, the hedgehog population is under pressure. 
53 A closer look at the research reports makes the situation even more puzzling: the biologists made most of their observations together and their descriptions are consistent with each other in almost every detail. Only one difference stands out: Whenever one of the biologists reports an attack by a kite, the other biologist describes an attack by a hawk. The two research reports seem to suggest systematic overdetermination of kiteand hawk-attacks on hedgehogs. How is that possible?

The puzzle disappears as soon as we learn that the two biologists use different taxonomies: one biologist considers kites to belong to the genus of hawks, while the other describes kites and hawks as two different genera. In such a situation, the problem of overdetermination disappears immediately because we are dealing not with two different causes, but only with two different descriptions of the same cause.

The obvious moral of the thought experiment is that different biological taxonomies lead to different causal descriptions but not to instances of overdetermination or causal competition. Different taxonomies do no causally compete with each other as they simply describe the causes in terms of different conceptual systems. According to pragmatic pluralism, the same is true in the case of mental and physical causation. We can describe the causes of human behaviour in terms of different conceptual systems such as physics, biology, or psychology. They might be equally fundamental in the sense that they cannot be reduced to some single and absolute ontology but that does not mean that they refer to ontological distinct realms of reality. And if there are no ontologically distinct causes, then there is also no overdetermination or causal competition.

The debates on phenomenal consciousness and mental causation illustrate Putnam's claim that not only the standard positions but also the most common problems in the philosophy of mind rest on dubious ontological assumptions. The idea of one single and absolute description of reality turns irreducibility into an unsolvable problem and obscures our understanding of causation by assuming one single and absolute description of causal processes. Pragmatic pluralism does not only require to rethink our metaphysical options in the philosophy mind but challenges the entire framework in which the mind-body problem has been discussed since the second half of the 20th century.

\section{BIBLIOGRAPHY}

BAKER L. R., (1997), “Why Constitution is not Identity,” Journal of Philosophy 94, 599-621.

CHALMERS D., (1996), The Conscious Mind, Oxford, Oxford University Press.

Chalmers D., (2009), “Ontological Anti-Realism," Metametaphysics, ed. Chalmers, Manly \& Wassermann, Oxford, Oxford University Press, 77-129.

EL-HANi C.N. \& S. PIHLSTRÖM, (2002), "Emergence Theories and Pragmatic Realism," Essays in Philosophy, 3 (2).

JACKSON F., (1982), “Epiphenomenal Qualia,” The Philosophical Quarterly, 127-36. 
KIM J., (1993), Supervenience and Mind. Cambridge, Cambridge University Press.

LYNCH M., (2001), Truth in Context: an Essay on Pluralism and Objectivity, Cambridge, The MIT Press.

NAGEL T., (1974), “What is it Like to be a Bat?," The Philosophical Review, 435-50.

OPPENHEIM P. \& H. PUTNAM, (1958), "Unity of Science as a Working Hypothesis," Minnesota Studies in the Philosophy of Science, vol. 2, 3-36.

POPPER K. R., (1978), “Three Worlds,” The Tanner Lectures on Human Values, Delivered at The University of Michigan, [[tannerlectures.utah.edu/lectures/documents/popper80.pdf]].

PUTNAM H., (1975a), Mind, Language, and Reality: Philosophical Papers, Volume 2, Cambridge, Cambridge University Press.

PUTNAM H., (1975b), “The Meaning of 'Meaning', Language, Mind and Knowledge. Minnesota Studies in the Philosophy of Science, 7, ed. Gunderson, Minneapolis, University of Minnesota Press, 131-93.

PUTNAM H., (1987), “Truth and Convention: On Davidson's Refutation of Conceptual Relativism,"

Dialectica, 41 (1-2), 69-77.

PUTNAM H., (1988), Representation and Reality, Cambridge, MIT Press.

PUTNAM H., (1992), “Why Functionalism Didn't Work," Inference, Explanation, and Other Frustrations: Essays in the Philosophy of Science, ed. J. Earman, Bertkeley and Los Angeles, University of California Press, 255-69.

PUTNAM H., (1999), The Threefold Cord. Mind, Body, and World, Chichester, Columbia University

Press.

PUTNAM H., (2004), Ethics without Ontology, Cambridge, Harvard University Press.

PRICE H., (1992), “Metaphysical Pluralism,” The Journal of Philosophy 89, 387-409.

ROSEN G. \& C. DORR, (2002), “Composition as Fiction," in Gale R. (ed.), The Blackwell Guide to Metaphysics, Oxford, Blackwell, 151-74.

SANFORD D., (2005), “Distinctness and Non-Identity,” Analysis, 6 (54), 269-74.

SOSA E., (1993) “Putnam's Pragmatic Realism Ernest,” The Journal of Philosophy, 90 (12), 605-26.

SOSA E., (1999), “Existential Relativity," Midwest Studies in Philosophy, 23 (1), 132-43.

VAN CLEVE J., (2008), "The Moon and Sixpence: A Defense of Mereological Universalism," Contemporary Debates in Metaphysics, 321-40.

YABlo S., (1992), “Mental Causation,” The Philosophical Review, 101/2, 245-80.

\section{ABSTRACTS}

Although Hilary Putnam has played a significant role in shaping contemporary philosophy of mind, he has more recently criticised its metaphysical foundations as fundamentally flawed. According to Putnam, the standard positions in the philosophy of mind rest on dubious ontological assumptions which are challenged by his "pragmatic pluralism" and the idea that we can always describe reality in different but equally fundamental ways. Putnam considers this pluralism about conceptual resources as an alternative to both physicalism and dualism. Contrary to physicalism, Putnam's pluralism rejects the ontological priority of physical concepts. Contrary to dualism, pragmatic pluralism denies that equally fundamental conceptual systems 
refer to ontologically distinct realms of reality. The aim of this paper is to discuss and clarify the implications of Putnam's pragmatic pluralism for the philosophy of mind. The first section introduces Putnam's concept of conceptual relativity and his rejection of an absolute ontology. In the second section, I argue that conceptual relativity leads to a pragmatic pluralism which undermines the common ontological framework of physicalism and dualism. The third section explains how pragmatic pluralists can reject identity claims without being committed to dualism. The last section discusses the implications of Putnam's pragmatic pluralism for the mind-body problem by focussing on phenomenal consciousness and mental causation.

\section{AUTHOR}

\section{DAVID LUDWIG}

Wageningen University - Netherlands

david.ludwig[at]wur.nl 